\title{
The distribution of reproductive risk factors disclosed the heterogeneity of receptor-defined breast cancer subtypes among Tanzanian women
}

\author{
Linus P. Rweyemamu 1,2, Gokce Akan ${ }^{3}$, Ismael C. Adolf², Erick P. Magorosa ${ }^{4}$, Innocent J. Mosha ${ }^{4}$, \\ Nazima Dharsee ${ }^{5}$, Lucy A. Namkinga', Sylvester L. Lyantagaye ${ }^{2}$, Abdolrahman S. Nateri ${ }^{6 *}$ and \\ Fatmahan Atalar $3,7^{*}$
}

\begin{abstract}
Background: Recent epidemiological studies suggest that reproductive factors are associated with breast cancer (BC) molecular subtypes. However, these associations have not been thoroughly studied in the African populations. The present study aimed to investigate the prevalence of $B C$ molecular subtypes and assess their association with reproductive factors in Tanzanian BC patients.

Methods: This hospital-based case-only cross-sectional study consisted of 263 histologically confirmed BC patients in Tanzania. Clinico-pathological data, socio-demographic characteristics, anthropometric measurements, and reproductive risk factors were examined using the Chi-square test and one-way ANOVA. The association among reproductive factors and $B C$ molecular subtypes was analyzed using multinomial logistic regression. The heterogeneity of the associations was assessed using the Wald test.

Results: We found evident subtype heterogeneity for reproductive factors. We observed that post-menopausal status was more prevalent in luminal-A subtype, while compared to luminal-A subtype, luminal-B and HER-2 enriched subtypes were less likely to be found in post-menopausal women (OR: $0.21,95 \% \mathrm{Cl} 0.10-0.41, p=0.001$; OR: 0.39 , $95 \% \mathrm{Cl} 0.17-0.89, p=0.026$, respectively). Also, the luminal-B subtype was more likely to be diagnosed in patients aged $\leq 40$ years than the luminal-A subtype (OR: $2.80,95 \% \mathrm{Cl} 1.46-5.32, p=0.002)$. Women who had their first fullterm pregnancy at $<30$ years were more likely to be of luminal-B (OR: $2.71,95 \% \mathrm{Cl} 1.18-4.17, p=0.018$ ), and triplenegative (OR: $2.28,95 \% \mathrm{Cl} 1.02-4.07, p=0.044)$ subtypes relative to luminal-A subtype. Furthermore, we observed that breastfeeding might have reduced odds of developing luminal-A, luminal-B and triple-negative subtypes. Women who never breastfed were more likely to be diagnosed with luminal-B and triple-negative subtypes when compared to luminal-A subtype (OR: $0.46,95 \% \mathrm{Cl} 0.22-0.95, p=0.035$; OR: $0.41,95 \% \mathrm{Cl} 0.20-0.85, p=0.017$, respectively).
\end{abstract}

\footnotetext{
*Correspondence: a.nateri@nottingham.ac.uk; fatmahan.atalar@gmail.com

${ }^{3}$ MUHAS Genetic Laboratory, Department of Biochemistry, Muhimbili University of Health and Allied Sciences, P.O Box 65001, Dar es Salaam, Tanzania

${ }^{6}$ Cancer Genetics and Stem Cell Group, Division of Cancer and Stem Cells,

School of Medicine, BioDiscovery Institute, University of Nottingham,

Nottingham NG7 2UH, UK

Full list of author information is available at the end of the article
}

(c) The Author(s) 2021. Open Access This article is licensed under a Creative Commons Attribution 4.0 International License, which permits use, sharing, adaptation, distribution and reproduction in any medium or format, as long as you give appropriate credit to the original author(s) and the source, provide a link to the Creative Commons licence, and indicate if changes were made. The images or other third party material in this article are included in the article's Creative Commons licence, unless indicated otherwise in a credit line to the material. If material is not included in the article's Creative Commons licence and your intended use is not permitted by statutory regulation or exceeds the permitted use, you will need to obtain permission directly from the copyright holder. To view a copy of this licence, visit http://creativecommons.org/licenses/by/4.0/. The Creative Commons Public Domain Dedication waiver (http//creativeco mmons.org/publicdomain/zero/1.0/) applies to the data made available in this article, unless otherwise stated in a credit line to the data. 
Conclusion: Our results are the first data reporting reproductive factors heterogeneity among BC molecular subtypes in Tanzania. Our findings suggest that breast-feeding may reduce the likelihood of developing luminal-A, luminal-B, and triple-negative subtypes. Meanwhile, the first full-term pregnancy after 30 years of age could increase the chance of developing luminal-A subtype, a highly prevalent subtype in Tanzania. More interventions to promote modifiable risk factors across multiple levels may most successfully reduce BC incidence in Africa.

Keywords: Breast cancer, Reproductive risk factors, Molecular subtype, Heterogeneity, Tanzania

\section{Introduction}

Breast cancer $(\mathrm{BC})$ is the most prevalent malignancy and the leading cause of cancer deaths globally. BC accounts for about $11.6 \%$ of all cancers worldwide, and reports showed that in 2018, 2.1 million new BC cases were diagnosed, of which 627,000 individuals lost their lives [1]. BC incidences are higher in developed countries than in developing countries, including subSaharan Africa (SSA), though mortalities are disproportionately higher in the latter [2]. In Tanzania, BC is the second most leading cause of mortality among women after cervical cancer [3, 4]. The age-standardized BC incidence is 19.4 new cases per 100,000 women, and the age-standardized mortality is 9.7 per 100,000 women, meaning that $50 \%$ of women diagnosed with $\mathrm{BC}$ in the country die of the disease. It is reported that about $80 \%$ of women diagnosed with BC in Tanzania present with a late-stage (stage III and IV) disease when the treatment is less effective and most patients cannot afford the treatment-associated costs [5].

$\mathrm{BC}$ is an umbrella term used to describe heterogeneous diseases diverse in morphology, pathology, histology, and molecular aspects [6]. The traditional BC classification depended on the histopathologic characteristics that encompass the tumor size, the nodal status, the local invasion, and the distant metastasis, which ultimately dictated the treatment modalities [7]. However, since the last two decades, BC classification has been overturned from pathologic types to molecular subtypes determined by gene expression profiling [8]. Gene expression profiling of $\mathrm{BC}$ is not yet fully available in many clinical settings due to its high costs and extensive resources needed [9]. Thus, the surrogate definition of $\mathrm{BC}$ molecular subtypes is based on immunohistochemistry (IHC) expression of three main protein markers; the estrogen receptor (ER), the progesterone receptor (PR), and the overexpression of human epidermal growth factor receptor-2 (HER-2/ neu). Additional markers such as proliferation index Ki-67 and basal cytokeratin 5/6 (CK5/6) are crucial in $\mathrm{BC}$ molecular subtyping, though not well adopted in most oncology diagnostic centers, particularly in SubSaharan Africa (SSA) [10, 11].
In many clinical settings, the standard $\mathrm{BC}$ management modalities mainly depend on the tumor molecular subtype that has changed the paradigm of $\mathrm{BC}$ treatment [8]. Based on ER, PR, and HER-2 key markers, four major BC molecular subtypes exist; Luminal-A, Luminal-B, HER-2 enriched, and Triple-negative/basal-like. These present subtypes of differences in incidence, prognosis, recurrence, response to the treatment regime, preference in metastatic organ, and survival outcome [7]. The risk factors for $\mathrm{BC}$ are well reviewed in the literature. Socio-demographic factors such as age at $\mathrm{BC}$ diagnosis, smoke exposure, alcohol consumption, body mass index (BMI) (obesity or overweight), family history of BC, and reproductive risk factors such as early menarche, late menopause, parity, age at first full-term pregnancy, breast-feeding, duration of breast-feeding and use of hormone replacement therapy (HRT) are associated with BC $[12,13]$.

Recent studies suggested that reproductive risk factors impact tumor subtypes of $\mathrm{BC}$ and $\mathrm{BC}$ etiology in women of different ethnic backgrounds worldwide [14]. Several studies have indicated that these reproductive risk factors are related to ER/PR receptors positive $\mathrm{BC}$ tumor subtypes [15-17]. A study in Northern China revealed that women aged 40 years or below who breast-fed for at least 12 months had a reduced risk of luminal-B and triplenegative subtypes while parity had a strong protection against luminal-A and luminal-B subtypes in both young and older women [14]. Indeed, parous women were more likely to be diagnosed with triple-negative subtype regardless of the age at $\mathrm{BC}$ diagnosis [18]. Also, a recently published study reported that the age of first pregnancy was significantly associated with the luminal-A subtype [19].

Nevertheless, the underlying biological mechanisms remain poorly understood and are still under investigation. Moreover, most of the available data regarding the $\mathrm{BC}$ molecular subtypes, their distribution and association with reproductive risk factors were derived from studies in Europe, America and Asia. Such studies are very limited in Africa, particularly in the East African population. Thus, the present study's objective was to establish the molecular subtype profiles of $\mathrm{BC}$ patients and then assess 
the association between the reproductive risk factors and these $\mathrm{BC}$ molecular subtypes.

\section{Methods}

\section{Study design and setting}

The present case-only hospital-based cross-sectional study was carried out at Ocean Road Cancer Institute (ORCI) between September 2019 and June 2020 in Tanzania. Tanzania is a lower-middle-income country in Eastern Africa with an estimated population of about 59 million in 2020. The country spans about $5^{\circ}$ south of the Equator, occupying an area of 945,087-square kilometers. ORCI is the only national specialized cancer facility located at the shores of the Indian Ocean in Dar es Salaam city, Tanzania. The facility was established back during German colonial times in 1895. It was declared an independent, autonomous institute by an Act of Parliament later in 1996. The ORCI, among other core services, provides the primary $\mathrm{BC}$ screening and treatment and receives referral cases from Muhimbili National Hospital $(\mathrm{MNH})$ and other private and public hospitals for Radiotherapy (including Brachytherapy), Chemotherapy, Hormonal/Endocrine therapy, Immunotherapy, and palliative care. The facility serves both local and foreign clients in which about 28,000 cancer confirmed patients, 10,000 cancer screening patients and 12,000 non-cancer patients are attended annually.

\section{Study population}

The study participants reported here were of Tanzanian origin/ethnicity, and confirmed the $\mathrm{BC}$ diagnosis with the histologic examination between June 2010 and January 2020. Patients of other ethnicities apart from Tanzanian, patients missing important clinico-pathological data in the file, and patients having a score of $2+$ for HER-2 expression were excluded. A total of 263 patients constituted the subset for this study. The participants recruited prospectively had their samples obtained as core biopsies following the hospital standard protocol. Ethical clearances with reference numbers $10 / \mathrm{Vol} / \mathrm{XX} / 16$ and NIMR/ $H Q / R .8 a / V o l . I X / 3255$ were issued by the host institute (ORCI) and Tanzania National Institute for Medical Research (NIMR), respectively. All methods were also performed following the relevant guidelines and regulations (Declaration of Helsinki). Written informed consent from each study participant was obtained.

\section{Data collection}

Participants were asked about their information as follows; socio-demographic characteristics including age, marital status (married, single and widowed), occupation (peasant, housewife, business and employed), place of origin, smoking during adolescence and adulthood (yes, no), alcohol during adolescence and adulthood (yes, no), anthropometric measurements (including height and weight) for BMI calculation (defined as $<25,25.0-30$ and $>30.0 \mathrm{~kg} / \mathrm{m}^{2}$ ), family history of BC (yes, no), and reproductive factors including menarche age $(<12,13-14$, $\geq 15$ years), parity (nulliparous, $1-2$ and $>3$ children), age at first full-term pregnancy ( $<30$ and $\geq 30$ years), breast-feeding (yes, no), breast-feeding duration (never, $>15$ and $\geq 15$ ), menopausal status (pre-menopausal, post-menopausal), HRT use (yes, no), oral contraceptive use (yes, no) and duration of oral contraceptive use $(<48$ and $\geq 48$ months) during face-to-face interviews by the well-trained and experienced nurses. Parity was defined as having one or more children. First, full-term pregnancy was defined as the first pregnancy that was completed at least 39 weeks. Post-menopausal status was defined as the cessation of menstrual cycles within the past 12 months prior to the interview. Pre-menopausal status was defined as regular menstrual cycles at 12 months. A physician extracted clinico-pathological data for all participants from their hospital electronic and/or physical files. Characteristics including metastasis status, status for tumor node metastasis (TNM) staging, tumor histological type, laterality, and age at $\mathrm{BC}$ diagnosis and treatment modalities at ORCI were abstracted.

\section{Molecular subtypes characterization}

The study material consisted of core needle or surgical samples fixed in $10 \%$ formalin. The classical histology techniques using hematoxylin and eosin staining were carried on formalin-fixed paraffin-embedded (FFPE) breast tissue blocks. The malignant tumors were classified according to the World Health Organization (WHO) classification of breast tumors [20] and graded with the criteria of Elston and Ellis [21]. The FFPE tissue sections were studied in the MNH pathology laboratory for histological analysis and IHC. The minority patients had undergone such examinations at either Kilimanjaro Christian Medical Center (KCMC), located in Kilimanjaro or Bugando Medical Center (BMC), located in Mwanza. The ER, PR, and HER2/neu status were determined by immunohistochemistry upon the FFPE blocks of breast carcinoma patients. Both ER and PR were scored based on an Allred scoring system that considers the percentage of stained cells (scale of $0-5$ ) and the staining intensity (scale of $0-3$ ). A minimum of $1 \%$ stained cells was considered for ER/PR positive tumors. An aggregate (from both percentages of stained cells and intensity) score of 3 or more was considered positive for ER and PR markers. HER-2 marker was scored on a scale of $0-3+$. A score of 0 or $1+$ was regarded as HER-2 negative, a score of $2+$ was regarded as equivocal (excluded in this study). 
In contrast, a score of $3+$ was regarded as HER-2 positive as per recommendations from the College of American Pathologists/American Society of Clinical Oncology (CAP/ASCO) [22]. The pathological stage was established based on tumor status, lymph node involvement status, and metastasis status as per the TNM staging system [23]. We classified BC cases into four major molecular subtypes based on IHC expression of ER/PR/HER-2 markers as shown below:

- Luminal-A (ER+/PR+/HER-2- or ER+/PR-/HER$2-$ or ER-/PR+/HER-2-),

- Luminal-B (ER+/PR+/HER-2+ or ER+/PR-/HER$2+$ or ER-/PR+/HER-2+),

- HER-2-enriched (ER-/PR-/HER-2+) and

- Triple-negative (ER-/PR-/HER-2-).

\section{Statistical analyses}

All data collected were organized in an excel database for windows 10 (Microsoft Corporation, Redmond, WA, USA) and analyzed in Statistical Package for Social Sciences 25.0 (IBM SPSS, Inc., Chicago, IL, USA). Differences between BC molecular subtypes about clinicopathologic, anthropometric, sociodemographic and reproductive characteristics were examined using OneWay ANOVA for the quantitative variables and Chisquare $\left(\mathrm{X}^{2}\right)$ tests for the categorical variables. The results were expressed as the mean \pm standard deviation, or percentage, wherever appropriate. Relative risks were assessed in $\mathrm{BC}$ molecular subtypes by calculating odds ratios (ORs) and 95\% confidence intervals (CIs) that were considered separate outcomes. Their respective risks were modelled via multinomial logistic regression. Heterogeneity was formally assessed with the Wald test, testing the null hypothesis that the risk associated with $\mathrm{BC}$ was the same across all molecular subtypes.

Additionally, multinomial logistic regression was performed using luminal-A cases as a reference group. The combined effect of parity and breast-feeding was also assessed on the risk of $\mathrm{BC}$ in all molecular subtypes using multivariable logistic regression. Analysis of covariance (ANCOVA) was used to determine possible confounders. We considered the following factors as potential confounders in all multivariable models: Age, BMI, and family history of BC (yes/no). Statistical significance was considered when $p<0.05$.

\section{Results}

A total of 263 BC patients with a mean age of $47.99 \pm 11.61$ years formed the study population. Most of the study participants were from urban areas (59.3\%). The most significant proportion of the present study cohort originated from the Northern zone of Tanzania (33.8\%). Table 1 summarizes the frequency of clinicopathological, anthropometric, sociodemographic characteristics and reproductive risk factors of the study population. Invasive ductal carcinoma of no specific type (IDC-NST) was the most prevalent histological tumor type in this study, accounting for $88.2 \%$. TNM pathologic stage III carcinomas were the most common, accounting for $55.5 \%, 27.4 \%$ stage IV, $15.6 \%$ stage II and $1.5 \%$ stage I.

The IHC data revealed that among 263 patients, $65.5 \%$ expressed hormone receptor-positive (ER+ and/or PR + ), 64.3\% expressed estrogen receptor-positive (ER+), 52.9\% expressed progesterone receptor-positive $(\mathrm{PR}+)$ and the proportion of patients overexpressing HER2 (HER2+) was $35.7 \%$ (Table 1). The largest proportions of cases were classified as luminal-A (44.5\%) followed by luminalB (22.4\%), triple-negative (22.1\%), and HER-2 enriched (11\%) subtype (Figs. 1 and 2).

$\mathrm{BC}$ was the most common in post-menopausal women (54.8\%), and within this group, the majority (63.2\%) had attained menopause before 50 years of age. Additionally, the majority $(52.1 \%)$ of the study group had late menarche (i.e. after 15 years old). Most BC patients in the present study had at least three children (56.3\%). The majority $(80.5 \%)$ had their first full-term pregnancy before 30 years of age, and $57.8 \%$ of the study cohort reported at least 15 cumulative months of breast-feeding. The $43 \%$ of BC patients had a history of contraceptive use with a mean duration of use of 69.64 months. With BMI $\left(\mathrm{kg} / \mathrm{m}^{2}\right)$, nearly $62 \%$ of the women were either overweight (27.4\%) or obese (34.6\%). Almost all (98.5\%) study participants were not exposed to smoking, and only $18.3 \%$ had used alcohol. The majority (79.1\%) of patients reported no history of $\mathrm{BC}$ in their families.

Table 2 shows the distribution of clinico-pathological parameters and reproductive risk factors in each subtype. The molecular subtypes differed significantly by histological type $(p=0.012)$. The triple-negative subtype showed the highest prevalence of invasive lobular carcinoma (ILC) histological type compared to other subtypes, $15.5 \%$ versus $2.6 \%$ luminal-A, $0 \%$ luminal-B and $3.4 \%$ HER-2 enriched. When we analyzed the reproductive risk factors in each subtype, we observed no heterogeneity in terms of menarche and family history of $\mathrm{BC}$ parameters among the four subtypes, as the differences of distributions were not statistically significant. Meanwhile, the subtypes differed significantly by age at diagnosis $(p=0.001)$. The Luminal-A subtype was more prevalent at older ages $($ mean $=48)$, and the luminal-B subtype was more prevalent at younger ages $($ mean $=39)$. Therefore, we assessed the possible interaction between reproductive factors and molecular subtypes using chi-square $\left(x^{2}\right)$ tests (Additional file 1: Table S1). To investigate the 
Table 1 Clinico-pathological, anthropometric and sociodemographic characteristics parameters of study group

\begin{tabular}{|c|c|}
\hline Characteristics & $\begin{array}{l}\text { Number of } \\
\text { patients, } \mathrm{n} \\
\text { (\%) }\end{array}$ \\
\hline Current age (years) mean $\pm S D$ & $47.99 \pm 11.61$ \\
\hline Age at diagnosis (years) mean $\pm S D$ & $44.49 \pm 10.81$ \\
\hline \multicolumn{2}{|l|}{ Histological type } \\
\hline IDC-NST & $232(88.2)$ \\
\hline ILC & $13(4.9)$ \\
\hline$M C$ & $5(1.9)$ \\
\hline Others & $13(4.9)$ \\
\hline \multicolumn{2}{|l|}{ TNM pathological stage } \\
\hline । & $4(1.5)$ \\
\hline$\|$ & $41(15.6)$ \\
\hline III & $146(55.5)$ \\
\hline IV & $72(27.4)$ \\
\hline \multicolumn{2}{|l|}{ Tumor laterality } \\
\hline Left & $127(48.3)$ \\
\hline Right & $127(48.3)$ \\
\hline Bilateral & $9(3.4)$ \\
\hline \multicolumn{2}{|l|}{ ERstatus } \\
\hline Positive (+) & $169(64.3)$ \\
\hline Negative (-) & $94(35.7)$ \\
\hline \multicolumn{2}{|l|}{ PR status } \\
\hline Positive (+) & $139(52.9)$ \\
\hline Negative (-) & $124(47.1)$ \\
\hline \multicolumn{2}{|l|}{ HER2 status } \\
\hline Positive (+) & $94(35.7)$ \\
\hline Negative (-) & $169(64.3)$ \\
\hline \multicolumn{2}{|l|}{ Molecular subtype } \\
\hline Luminal-A & $117(44.5)$ \\
\hline Luminal-B & $59(22.4)$ \\
\hline HER-2 enriched & $29(11.0)$ \\
\hline Triple-negative & $58(22.1)$ \\
\hline \multicolumn{2}{|l|}{ Menopausal status } \\
\hline Pre-menopause & $119(45.2)$ \\
\hline Post-menopause & $144(54.8)$ \\
\hline$<50$ years old & $91(63.2)$ \\
\hline$\geq 50$ years old & $53(36.8)$ \\
\hline \multicolumn{2}{|l|}{ Family history of $B C$} \\
\hline Yes & $55(20.9)$ \\
\hline No & $208(79.1)$ \\
\hline \multicolumn{2}{|l|}{ BMI } \\
\hline Normal weight $<25 \mathrm{~kg} / \mathrm{m}^{2}$ & $100(38)$ \\
\hline Overweight $25-30$ kg/m² & $72(27.4)$ \\
\hline Obese $>30 \mathrm{~kg} / \mathrm{m}^{2}$ & $91(34.6)$ \\
\hline \multicolumn{2}{|l|}{ Menarche } \\
\hline Early $<12$ years old & $11(4.2)$ \\
\hline Normal 13-14 years old & $115(43.7)$ \\
\hline Late $>15$ years old & $137(52.1)$ \\
\hline Age at first full-term pregnancy & \\
\hline
\end{tabular}

Table 1 (continued)

\begin{tabular}{|c|c|}
\hline Characteristics & $\begin{array}{l}\text { Number of } \\
\text { patients, } n \\
(\%)\end{array}$ \\
\hline$<30$ years old & $198(80.5)$ \\
\hline$\geq 30$ years old & $48(19.5)$ \\
\hline \multicolumn{2}{|l|}{ Parity } \\
\hline Nulliparous & $27(10.3)$ \\
\hline 1-2 Children & $88(33.5)$ \\
\hline$\geq 3$ Children & $148(56.3)$ \\
\hline \multicolumn{2}{|l|}{ Breast-feeding } \\
\hline Breast-feeding duration (months) mean \pm SD & $15.5 \pm 6.5$ \\
\hline Never & $63(24)$ \\
\hline Yes & $200(76)$ \\
\hline$<15$ months & $48(18.3)$ \\
\hline$\geq 15$ months & $152(57.8)$ \\
\hline \multicolumn{2}{|l|}{ Contraceptive use } \\
\hline Yes & $113(43)$ \\
\hline$<48$ months & $34(30.1)$ \\
\hline$\geq 48$ months & $79(69.9)$ \\
\hline No & $150(57)$ \\
\hline \multicolumn{2}{|l|}{ HRT use } \\
\hline Yes & $0(0)$ \\
\hline No & $263(100)$ \\
\hline \multicolumn{2}{|l|}{ Smoke exposure } \\
\hline Yes & $4(1.5)$ \\
\hline No & $259(98.5)$ \\
\hline \multicolumn{2}{|l|}{ Alcohol consumption } \\
\hline Yes & $48(18.3)$ \\
\hline No & $215(81.7)$ \\
\hline \multicolumn{2}{|l|}{ Residance } \\
\hline Rural & $107(40.7)$ \\
\hline Urban & $156(59.3)$ \\
\hline \multicolumn{2}{|l|}{ Place of origin } \\
\hline Central zone & $37(14.1)$ \\
\hline Western zone & $14(5.3)$ \\
\hline Eastern zone & $50(19)$ \\
\hline Northern zone & $89(33.8)$ \\
\hline Southern zone & $55(20.9)$ \\
\hline Lake zone & $18(6.8)$ \\
\hline \multicolumn{2}{|l|}{ Occupation } \\
\hline Peasant & $107(40.7)$ \\
\hline Housewife/dependant & $70(26.6)$ \\
\hline Business/entrepreneur & $63(24)$ \\
\hline Employed & $16(6.1)$ \\
\hline Others & $7(2.6)$ \\
\hline \multicolumn{2}{|l|}{ Marital status } \\
\hline Married & $179(68.1)$ \\
\hline Single & $25(9.5)$ \\
\hline Widowed/separated/divorced & $59(22.4)$ \\
\hline
\end{tabular}

TNM tumor node metastasis, IDC-NST Invasive ductal carcinoma of no specific type, ILC Invasive lobular carcinoma, $M C$ mucinous carcinoma, ER estrogen receptor, $P R$ progesterone receptor, HER2 Human epidermal growth factor receptor 2, BMI body mass index, $H R T$ hormone replacement therapy, $S D$ Standard deviation 


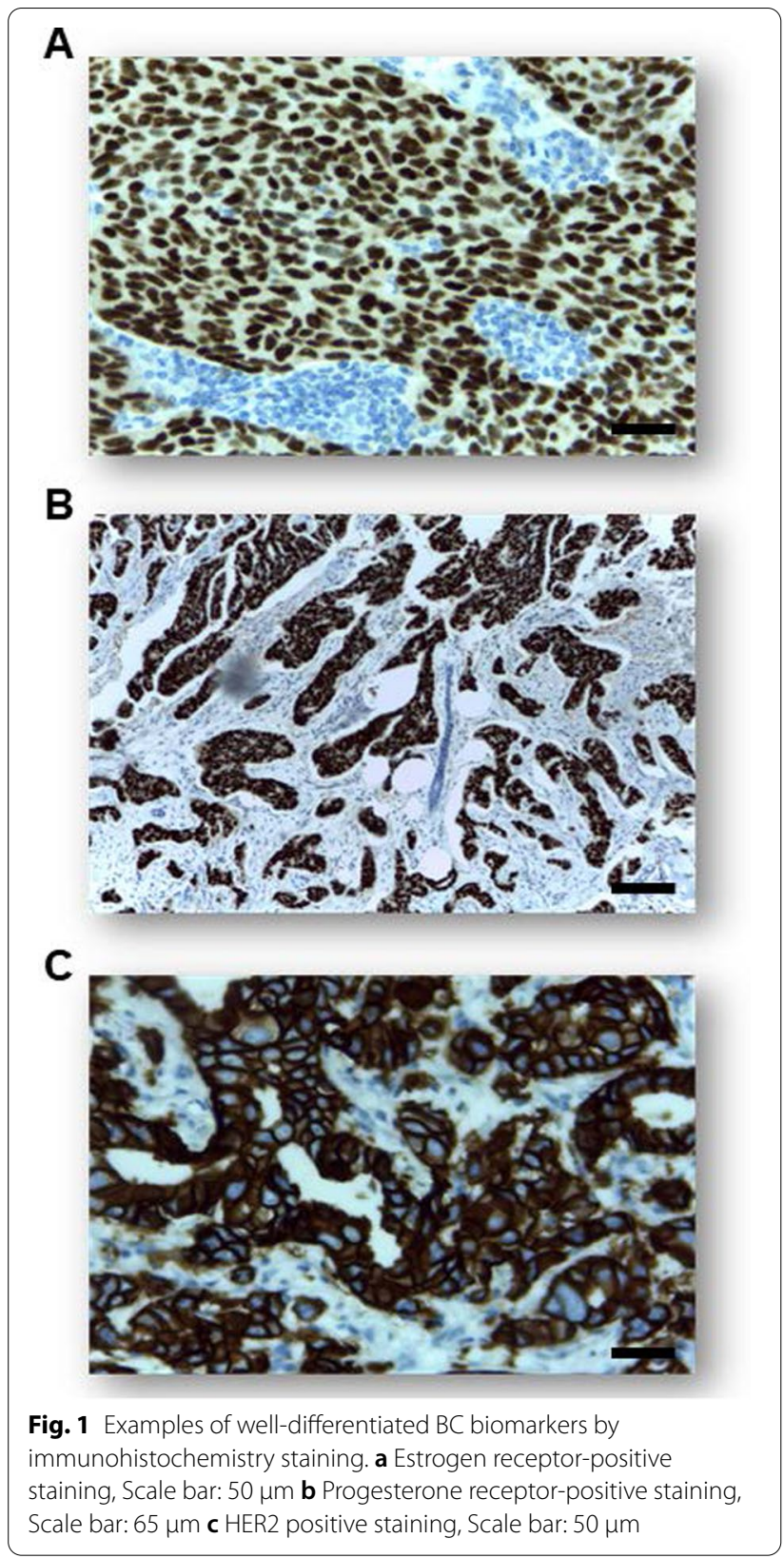

association between age at $\mathrm{BC}$ diagnosis and molecular subtypes, we divided breast cancer patients into two subgroups according to the age at $\mathrm{BC}$ diagnosis $(<40$ years old and $\geq 40$ years old). Compared to other subtypes (44.2\%), the luminal-A subtype (62.1\%) was found to be more likely diagnosed at the age of $\geq 40$ years (OR: 2.06 , 95\%CI 1.14-3.70, $p=0.014$ ).

Molecular subtypes also showed a very significant difference according to menopausal status $(p=0.001)$. Indeed, luminal-A and triple-negative subtypes $(67.5 \%$ and $60.9 \%$, respectively) were post-menopausal, while

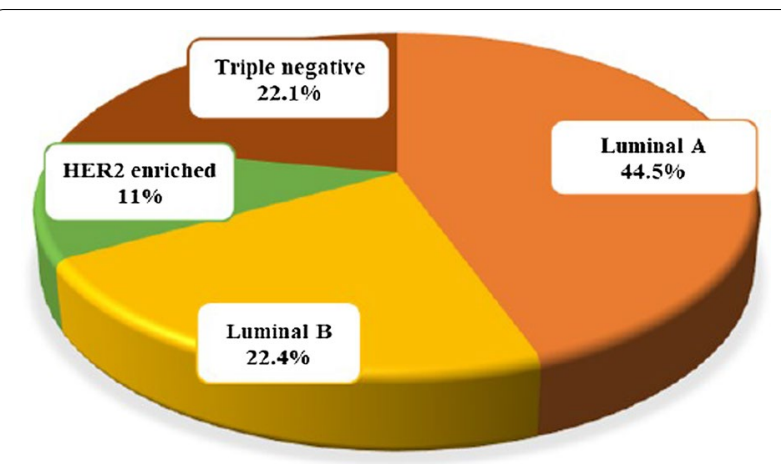

Fig. 2 Distribution of cases as per molecular subtypes. The values were calculated using the Chi-square test, and the data were expressed in percentages. The figure was generated using GraphPad Prism version 8.0 (GraphPad Software Inc., San Diego, CA, USA)

luminal-B and HER-2 enriched subtypes $(69.5 \%$ and $55.2 \%$, respectively) were pre-menopausal. When we analyzed menopausal status in all subtypes separately, the luminal-A subtype showed a higher likelihood of being post-menopausal than other non-luminal-A (44.2\%) subtypes (OR: 2.69, 95\%CI 1.16-4.47, $p=0.001$ ). Meanwhile, the luminal-B subtype was more likely to be pre-menopausal than the non-luminal-B (38.2\%) subtypes (OR: $3.89,95 \%$ CI 2.07-7.33, $p=0.001)$.

Furthermore, there was heterogeneity in terms of parity, breast-feeding, and breast-feeding duration among subtypes. Most of the luminal-A cases had $\geq 1$ child and breast-fed for $\geq 15$ months compared to other subtypes, but the differences were not statistically significant. We divided the $\mathrm{BC}$ patients into two subgroups to investigate the possible interaction of parity and luminal-A subtype (Nulliparous and $\geq 1$ Child). We observed that nulliparous women was more likely to have luminal-A subtype (14.7\%) than non-luminal-A (5.4\%) cases (OR: 2.15, 95\%CI $0.93-4.94, p=0.035)$. In addition, women who had their first full-term pregnancy at $\geq 30$ years old had a more likelihood of having luminal-A subtype than nonluminal-A (14.5\%) subtypes (OR: 0.50, 95\%CI 0.26-0.95, $p=0.004)$. A majority of the patients (82.1\%) with luminal-A subtype had also breast-fed their babies. When compared luminal-A subtypes (17.9\%) to non-luminalA subtypes (31.3\%), we noted that women who breastfed were less likely to be of luminal-A subtype (OR: 2.1, 95\%CI 1.17-3.78, $p=0.009$ ).

Further, we analyzed the combined effect of parity and breast-feeding as a risk factor of $\mathrm{BC}$ in all subtypes. We divided $\mathrm{BC}$ patients into three subgroups; the first group was women with $\geq 1$ full-term pregnancy who breastfed for at least 15 months. The second group was those with $\geq 1$ full-term pregnancy who never breast-fed, and the third group was nulliparous women. Our findings 
Table 2 Characteristics and reproductive factors of BC patients by molecular subtypes

\begin{tabular}{|c|c|c|c|c|c|}
\hline Characteristics & Luminal-A $(n=117)$ & Luminal-B $(n=59)$ & $\begin{array}{l}\text { HER-2 } \\
\text { enriched } \\
(n=29)\end{array}$ & Triple-negative $(n=58)$ & $p$ value \\
\hline Age at diagnosis (years) $)^{a}$ & $48.78 \pm 12.19$ & $39.73 \pm 6.40$ & $41.76 \pm 9.14$ & $44.49 \pm 10.81$ & 0.001 \\
\hline \multicolumn{6}{|l|}{ Histological type, $n(\%)^{b}$} \\
\hline IDC-NST & $105(89.7)$ & $55(93.2)$ & $26(89.7)$ & $46(79.3)$ & \multirow[t]{4}{*}{0.012} \\
\hline ILC & $3(2.6)$ & $0(0)$ & $1(3.4)$ & $9(15.5)$ & \\
\hline MC & $2(1.7)$ & $2(3.4)$ & $1(3.4)$ & $0(0)$ & \\
\hline Others & $7(6)$ & $2(3.4)$ & $1(3.4)$ & $3(5.2)$ & \\
\hline \multicolumn{6}{|c|}{ TNM pathological stage, $n(\%)^{b}$} \\
\hline । & $1(0.9)$ & $0(0)$ & $2(6.9)$ & $1(1.7)$ & \multirow[t]{4}{*}{0.059} \\
\hline$\|$ & $24(20.5)$ & $4(6.8)$ & $2(6.9)$ & $11(19)$ & \\
\hline III & $64(54.7)$ & $33(55.9)$ & $15(51.7)$ & $34(58.6)$ & \\
\hline IV & $28(23.9)$ & $22(37.3)$ & $10(34.5)$ & $12(20.7)$ & \\
\hline \multicolumn{6}{|l|}{ Tumor laterality, $n(\%)^{b}$} \\
\hline Left & $60(51.3)$ & $31(52.5)$ & $11(37.9)$ & $25(43.1)$ & \multirow[t]{3}{*}{0.377} \\
\hline Right & $53(45.3)$ & $27(45.8)$ & $18(62.1)$ & $29(50)$ & \\
\hline Bilateral & $4(3.4)$ & $1(1.7)$ & $0(0)$ & $4(6.9)$ & \\
\hline \multicolumn{6}{|l|}{ Menopausal status, $n(\%)^{b}$} \\
\hline Pre-menopause & $38(32.5)$ & $41(69.5)$ & $16(55.2)$ & $24(39.1)$ & \multirow[t]{2}{*}{0.001} \\
\hline Post-menopause & $79(67.5)$ & $18(30.5)$ & $13(44.8)$ & $34(60.9)$ & \\
\hline \multicolumn{6}{|l|}{ Family history of $B C, n(\%)^{b}$} \\
\hline Yes & $25(21.4)$ & $12(20.3)$ & $4(13.8)$ & $14(24.1)$ & \multirow[t]{2}{*}{0.734} \\
\hline No & $92(78.6)$ & $47(79.7)$ & $25(86.2)$ & $44(75.9)$ & \\
\hline \multicolumn{6}{|l|}{ Menarche, $n(\%)^{b}$} \\
\hline Early $<12$ years old & $5(4.3)$ & $3(5.1)$ & $2(6.9)$ & $1(1.7)$ & \multirow[t]{3}{*}{0.802} \\
\hline Normal $13-14$ years old & $54(46.1)$ & $27(45.7)$ & $10(34.5)$ & $24(41.4)$ & \\
\hline Late $>15$ years old & $58(49.6)$ & $9(49.2)$ & $17(58.6)$ & $33(56.9)$ & \\
\hline \multicolumn{6}{|c|}{ Age at first full-term pregnancy, $n(\%)^{b}$} \\
\hline$<30$ years old & $75(74.8)$ & $46(86.8)$ & $21(79.3)$ & $43(87.8)$ & \multirow[t]{2}{*}{0.145} \\
\hline$\geq 30$ years old & $25(25.2)$ & $9(13.2)$ & $6(20.7)$ & $10(12.2)$ & \\
\hline \multicolumn{6}{|l|}{ Parity, $n(\%)^{b}$} \\
\hline Nulliparous & $17(13.7)$ & $4(6.8)$ & $2(6.9)$ & $5(10.3)$ & \multirow[t]{3}{*}{0.103} \\
\hline 1-2 Children & $35(30.8)$ & $26(44.1)$ & $7(24.1)$ & $20(33.8)$ & \\
\hline$\geq 3$ Children & $65(55.6)$ & $29(49.2)$ & $20(69)$ & $33(55.9)$ & \\
\hline \multicolumn{6}{|l|}{ Breast-feeding, $n(\%)^{b}$} \\
\hline Yes & $96(82.1)$ & $40(67.8)$ & $22(75.9)$ & $38(65.5)$ & \multirow[t]{2}{*}{0.058} \\
\hline No & $21(17.9)$ & $19(32.2)$ & $7(24.1)$ & $20(25.5)$ & \\
\hline \multicolumn{6}{|c|}{ Breast-feeding duration, $n(\%)^{b}$} \\
\hline$<15$ months & $19(19.8)$ & $10(25)$ & $6(27.3)$ & $12(31.6)$ & \multirow[t]{2}{*}{0.516} \\
\hline$\geq 15$ months & $77(80.2)$ & $30(75)$ & $16(72.7)$ & $26(68.4)$ & \\
\hline
\end{tabular}

The $p$-values less than 0.05 (typically $\leq 0.05$ ) as being statistically significant and were bolded

TNM tumor node metastasis, HER2 human epidermal growth factor receptor-2, IDC-NST invasive ductal carcinoma of no specific type, ILC invasive lobular carcinoma, $M C$ mucinous carcinoma

${ }^{a}$ The values are calculated using one-way ANOVA and the data are given mean \pm standard deviation

${ }^{\mathrm{b}}$ The values are calculated using Chi-square test and the data are expressed in percentages. In all cases, differences were considered significant at $p<0.05$

revealed that women with $\geq 1$ full-term pregnancy who breast-fed at least 15 months were less likely to develop luminal-A subtype than non-luminal-A cases. However, this difference was not statistically significant (OR: 1.09, 95\%CI 0.25-1.25, $p=0.506$ ) (data not shown).

Subsequently, we assessed associations between reproductive factors and subtypes by multinomial 
Table 3 The odds ratios and 95\% confidence intervals of reproductive risk factors by BC subtypes

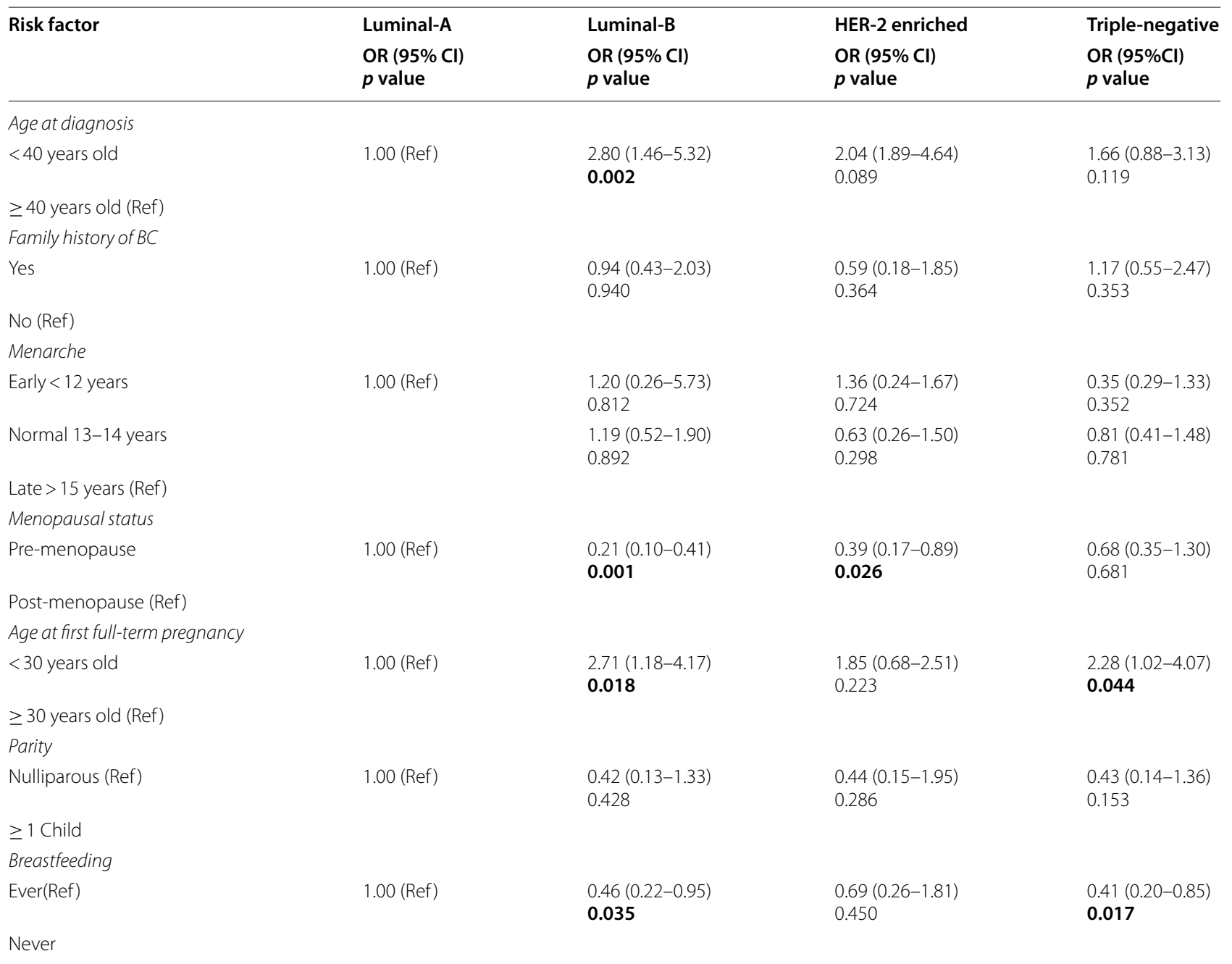

The $p$-values less than 0.05 (typically $\leq 0.05$ ) as being statistically significant and were bolded

The ORs and $95 \% \mathrm{Cls}$ were found by multinomial logistic regression comparing luminal-A cases as the reference group. All odds ratios (OR) are adjusted age, BMI and family history of $\mathrm{BC}$ (yes, no). In all cases, differences were considered significant at $p<0.05$

$\mathrm{Cl}$ confidence interval, $\mathrm{OR}$ odds ratio, HER2 human epidermal growth factor receptor 2 , Ref reference

logistic regression analysis, and the results are shown in Table 3. We observed that women aged 40 years or younger were more likely to develop the luminal-B subtype than the luminal-A subtype (OR: $2.80,95 \% \mathrm{CI}$ $1.46-5.32, p=0.002)$. Moreover, when women having first full-term pregnancy at or after 30 years of age were taken as a reference group, we noted that women having the first full-term pregnancy before 30 years old were more likely to being luminal-B (86.3\%) and triplenegative $(87.8 \%)$ subtypes when compared to luminalA subtype (OR: $2.71,95 \%$ CI $1.18-4.17, p=0.018$; OR: $2.28,95 \%$ CI 1.02-4.07, $p=0.044$, respectively). Similarly, when breast-fed women were taken as references group; the women who never breast-fed were more likely to develop luminal-B (32.2\%) and triple-negative
(25.5\%) subtypes when compared to luminal-A subtype (OR: $0.46,95 \%$ CI $0.22-0.95, p=0.035$; OR: $0.41,95 \%$ CI $0.20-0.85, p=0.017$, respectively).

The effect of menopausal status was heterogeneous across the subtypes ( $p_{\text {heterogeneity }}=0.001$ ). Post-menopause women as a reference group, pre-menopausal status was more prevalent in luminal-B (69.5\%) and HER-2 enriched (55.2\%) subtypes. Post-menopause women were less likely to develop luminal-B, and HER-2 enriched subtypes compared to luminal-A subtype (OR: $0.21,95 \%$ CI $0.10-0.41, p=0.001$; OR: 0.39 , $95 \%$ CI $0.17-0.89, p=0.026$, respectively). In contrast, there was no statistical evidence of heterogeneity for family history of $\mathrm{BC}$, menarche, and parity among $\mathrm{BC}$ subtypes $\left(\mathrm{p}_{\text {heterogeneity }}>0.05\right)$. 


\section{Discussion}

In this case-only hospital-based cross-sectional study, we observed that majority of the $\mathrm{BC}$ patients enrolled came from urban residences rather than rural residences. We observed that a substantial number of BC patients originated from the Northern part of Tanzania compared to the other zones. We speculated that the women have limited reach to diagnostic facilities in rural residences and possibly die with $\mathrm{BC}$ undiagnosed. Similar speculations were presented from different regions of Africa [24].

The IHC evaluation among $263 \mathrm{BC}$ patients resulted in nearly $70 \%$ of $\mathrm{BC}$ patients expressing $\mathrm{ER}$ and/or PR receptors markers; hence can benefit from hormonal therapy. We also observed that luminal-A comprises the most common subtypes among the studied population $(44.5 \%)$, and this was followed by luminal-B (22.4\%), triple-negative (22.1\%) and HER-2 enriched (11\%) (Fig. 2). A similar BC molecular subtypes prevalence pattern was reported in Eastern Africa country, Ethiopia [10] and Northern Africa country, Morocco [25] whereby luminalA was the commonest subtype and HER-2 enriched was the rarest subtype. Other studies from Asian and European countries have also reported the highest prevalence of luminal-A subtype in their regions [26, 27]. Our findings differ from the Tanzanian report that showed nearly half (45.6\%) of cases previously analyzed for ER, PR and HER-2 receptor status were triple-negative [28]. The difference might be attributed to their small sample size being only $53 \mathrm{BC}$ samples analyzed for hormonal receptors, thereby limiting comparability with our findings.

However, our findings differ from many African studies, as summarized in Additional file 1: Table S2. Most African studies show that triple-negative ranks the first or the second most prevalent subtype among women diagnosed with BC [29]. Triple-negative tumors are aggressive, younger age at diagnosis, and are most frequently seen in BC patients of African ancestry [30]. The relatively low prevalence of triple-negative subtypes observed in this study could be due to the study design. The data presented here are of $\mathrm{BC}$ patients diagnosed with the disease between 2010 and 2020 and who consented to participate. There might be a significant number of triple-negative $\mathrm{BC}$ patients who died during treatment, considering that triple-negative tumors are aggressive and patients have shorter survival compared to other subtypes [30]. Indeed, African data on the distribution of molecular subtypes are inconsistent, perhaps due to many factors, including study design and relatively small sample-sized studies. Triple-negative subtype might be overestimated in many African settings due to the lack of adequate state of the art facilities needed to fix paraffin-embedded tissues and antibodies staining rendering many tumors negative for ER, PR and HER-2 markers.

Histopathological analysis showed that IDC-NST was the most prevalent histologic type in this study cohort ranging from 78.3 to $93.2 \%$ in all four BC subtypes. This prevalence is consistent with the findings from other published studies in various African and Asian countries [31, 32]. The ILC was the second most frequent and was significantly abundant in triple-negative subtypes $(75.2 \%$, $p=0.014$ ) in our study, which partly matches the findings from the retrospective study in the Kingdom of Saudi Arabia [33], and conflicts with the findings from Northern Africa that showed ILC was more abundant in luminal-A subtypes [34].

We further analyzed the association of reproductive risk factors and $\mathrm{BC}$ molecular subtypes. Reproductive risk factors were differentially associated with molecular subtypes of $\mathrm{BC}$ in the present study. We observed a clear BC molecular subtypes heterogeneity for reproductive factors. The most prominent reproductive factors were age at $\mathrm{BC}$ diagnosis, menopausal status, parity, age at the first full-term pregnancy, and breast-feeding in different age groups. The $\mathrm{BC}$ molecular subtypes differed significantly by age at $\mathrm{BC}$ diagnosis. The luminal- $\mathrm{B}$ subtype was more prevalent at younger ages $($ mean $=39)$, and the luminal-A subtype was more prevalent at older ages $($ mean $=48)$. Women 40 years of age or older had a more likelihood of being diagnosed with luminal-A subtype. Hence, $40+$ years of age is a likely risk factor for the luminal-A subtype in our study cohort. Previous studies have examined the association of age at $\mathrm{BC}$ diagnosis and molecular subtypes. A study in Turkish women demonstrated that advanced age (40+ years) was a risk factor for both luminal-A and triple-negative subtypes [35].

On the other hand, studies in Western countries and the USA show that the triple-negative subtype is more likely to be diagnosed at a younger age [30]. This was not observed in this study as the mean age at $\mathrm{BC}$ diagnosis for triple-negative and HER-2 enriched subtypes were almost the same (Table 2). In addition, the analysis of multinomial logistic regression showed that the luminal-B subtype was more likely to be diagnosed among women aged 40 years or younger than the luminal-A subtype (Table 3).

In this study, hormonal receptor-positive subtypes (luminal-A and luminal-B) were differential in menopausal status. Women who had attained menopause (postmenopausal) were likely to be of luminal-A subtype, whereas pre-menopausal women were determined to be of luminal-B subtype. Additionally, our multinomial logistic regression analysis supported these results. A prior study by Turkoz et al. reported that postmenopausal women who used HRT for more than 5 years had 
increased odds of developing luminal-A subtype [35]. However, in our study, none of the study participants reported using HRT.

Parity was another related reproductive risk factor of $B C$ in our study population. Our findings showed that the luminal-A subtype was more likely to be diagnosed in nulliparous women. Thus, it is suggested that having one or more children could be a strong protective factor against the $\mathrm{BC}$ of the luminal-A subtype. Several studies have explored the association of parity and $\mathrm{BC}$ molecular subtypes. A meta-analysis review by Lambertini et al. revealed that parity correlated with a significant reduction in risk of developing hormonal receptor-positive BC in parous women [36]. A similar finding was observed in a study from Northern China women aged below 41 years [14]. The mechanism on how parity decreases the risk of $\mathrm{BC}$ in luminal subtypes is postulated to be through modulation of circulating ER and PR hormones and acceleration of mammary gland tissues differentiation [37].

On the other hand, parity was reported to be associated with an increased risk for triple-negative subtypes in women irrespective of age at diagnosis [18]. Previous studies also showed that pregnancy has a cross effect for BC risk as a short-term effect. Pregnancy transiently increases the $\mathrm{BC}$ risk after birth due to stimulating the malignant cell transformation. However, as a long-term effect, it reduces the $\mathrm{BC}$ risk in later years due to inducing the differentiation of normal mammary stem cells [38]. More comprehensive case-control research is warranted in the SSA population to understand parity's biological role in different $\mathrm{BC}$ molecular subtypes.

We demonstrated that the luminal-A subtype was more likely to be found in women with the first full-term pregnancy at 30 years or above compared to other subtypes. Our findings corroborates with previous studies that showed that having the first full-term pregnancy at 24 years or more increased the risk of hormonal receptorpositive BC [36]. A prior study in the Turkish population reported that women with the first full-term pregnancy after age 30 also had a significantly elevated risk of luminal BC [35]. Additionally, a recent study in women aged $40+$ years of Northern China revealed similar results [14]. Another study in Latin American countries revealed that older age at the first full-term pregnancy was positively associated with the risk of BC overall [39].

Moreover, a recently published study observed that the first delivery at age $\geq 31$ was associated with an increased risk of both IDC and ILC BC tumor subtypes in Iranian BC women [40]. The Breast Cancer Association Consortium (BCAC) reported that parity decreases the risk of $\mathrm{BC}$ by $16 \%$, and each live birth reduces the risk of developing $\mathrm{BC}$ by $11 \%$. Meanwhile, each 5 -year increment in the age at first full-term pregnancy and the birth age was associated with a 7\% increase in the risk of developing BC [41]. Our regression analysis showed that women with the first full-term pregnancy before 30 years were more likely to be diagnosed with luminal-B and triple-negative subtypes relative to the luminal-A subtype. Our observation partly agrees with Brouckaert et al. that reported a non-linear association of increasing age at first full-term pregnancy and triple-negative subtype [18].

Various studies show that breast-feeding for at least 6 months has protection against luminal subtypes [35] and triple-negative subtypes [42]. However, a recent caseonly study from Kenya, an East Africa country, reported a lack of association of breast-feeding across all BC subtypes even after age stratification [43]. Our study showed that breast-feeding had a significant inversely association with luminal-A, luminal-B and triple-negative subtypes relative to women who never breast-fed. The majority of participants (57.8\%) in this study cohort had breast-fed their babies at least 15 months. The effect of long-term breast-feeding has been reported to be overall protection against all BC subtypes [39]. Our data showed likely protection against luminal and triple-negative subtypes however there should be an accelerated effort to encourage Tanzanian women and other Africans, in general, to breast-feed their babies for a longer period as breastfeeding has positive outcomes for both the mother and the child. The mechanism of how breast-feeding protects against $\mathrm{BC}$ is well described in the literature. This protection works via hormonal mechanisms such as reducing estrogen levels in breast tissues, differentiation in mammary tissues, and apoptosis in progenitor cells [12, 44, 45].

Furthermore, we analyzed the combined effect of parity and breast-feeding in this study cohort. Our data revealed a non-significant decreased odds of developing luminal-A among women with at least one full-term pregnancy and breast-feeding. Contrary to our findings, a USA study reported that women under 50 years who had at least three full-term pregnancies and did not or breastfed for less than 12 months had a twofold increased risk of triple-negative subtype [46]. We further recommend more extended period breast-feeding practice among parous African women. It has been shown that parity and breast-feeding are the modifiable risk factors, hence, considered indispensable tools toward $\mathrm{BC}$ prevention strategies.

Family history is a well-known risk factor of $\mathrm{BC}$, but we could not find heterogeneity in $\mathrm{BC}$ or other types of cancers among the subtypes. Similar results were observed in a PreFace study that analyzed 3392 post-menopausal patients with hormone receptor-positive early BC in Germany [47] and a study of Turkish women [35]. However, contrary to our study, findings from South-East Asian 
ethnic groups reported that family history was only associated with triple-negative subtype after adjustment for grade or stage at BC diagnosis [48]. Additionally, our analysis found no heterogeneity of age at menarche among the four $\mathrm{BC}$ molecular subtypes. This was in agreement with the findings from the population-based case-case study in the USA [46] and divergent to a study in China that found women aged 13 years or below had increased odds of developing basal-like BC [47].

The strength of the current work has given the first impression of the prevalence of $\mathrm{BC}$ molecular subtypes and their association with reproductive factors in Tanzanian BC patients. However, our study has some limitations:

1. Our study did not consider survivorship bias across the four $\mathrm{BC}$ subtypes. It is known that triple-negative $\mathrm{BC}$ patients have the poorest survival when compared to other subtypes.

2. The case-only study design introduces some cautions in interpretation. Our sample size is relatively small (263 patients), and the design was a case-only study, not a case-control study that would have given the absolute risks of $\mathrm{BC}$. In addition, $\mathrm{BC}$ molecular subtyping was based on IHC markers status since gene expression profiling is not available in clinical settings in most resource-poor countries like Tanzania. Still, it is powerful enough to give the first impression of $\mathrm{BC}$ etiology heterogeneity among the subtypes in a population of poor-resources.

3. IHC BC molecular classification did not include proliferative index Ki-67 and basal cytokeratin 5/6 (CK5/6).

These markers are not routinely performed in hospitals in resource-poor settings. Having data on these markers would help us further classify triple-negative cases into basal-like and normal-like subtypes. In addition, Ki-67 would help us classify exactly luminal-A and luminal-B subtypes.

\section{Conclusions}

In conclusion, to the best of our knowledge, this is the first study from Tanzania to demonstrate the association between the $\mathrm{BC}$ molecular subtypes and the reproductive factors. Also, our data add to the existing knowledge of reproductive factors heterogeneity among $\mathrm{BC}$ molecular subtypes for Eastern African BC patients. The results showed that reproductive risk factors (menopausal status, parity, age at first full-term pregnancy, and breast-feeding) were associated with luminal BC in Tanzanian women. In general, older and post-menopausal women were more likely to be diagnosed with luminal-A subtype. In contrast, young and pre-menopausal women were more likely to be diagnosed with luminal-B subtype in Tanzanian BC patients.

Overall, our data concordance with recent publications, suggesting that breast-feeding may reduce the likelihood of developing luminal-A, luminal-B, and triple-negative subtypes. At the same time, the first full-term pregnancy after 30 years of age could increase the chance of developing luminal-A subtype, which is a highly prevalent subtype in Eastern African Tanzanian BC patients. Our study has presented the preliminary findings. Future work needs to be performed in large cohorts, a case-control study is required to confirm these associations of reproductive factors and $\mathrm{BC}$ subtypes in Africa.

\section{Abbreviations \\ SSA: Sub-Saharan Africa; BC: Breast cancer; IDC-NST: Invasive ductal carcinoma of no specific type; ILC: Infiltrating lobular carcinoma; IHC: Immunohisto- chemistry; BMI: Body mass index; EGFR: Epidermal growth factor receptor; ER: Estrogen receptor; HER2: Human epidermal growth factor receptor 2; HR: Hormonal receptor; HRT: Hormone replacement therapy; PR: Progesterone receptor; TNM: Tumor node metastasis; FFPE: Formalin-fixed paraffin-embed- ded; ORCI: Ocean Road Cancer Institute; MNH: Muhimbili National Hospital; KCMC: Kilimanjaro Christian Medical Center; BMC: Bugando Medical Center; NIMR: National Institute for Medical Research; MOEST: Tanzania Ministry of Education, Science and Technology; WHO: World Health Organization; BCAC : Breast Cancer Association Consortium; CAP/ASCO: College of American Pathologist/American Society of Clinical Oncology; Cl: Confidence interval; OR: Odds ratio; $\times 2$ : Chi-square.}

\section{Supplementary Information}

The online version contains supplementary material available at https://doi. org/10.1186/s12905-021-01536-6.

Additional file 1. The odds ratios and $95 \%$ confidence intervals of associated reproductive factors by BC subtypes (Table $\mathrm{S} 1$ ) and Distribution of BC molecular subtypes among selected African countries (Table S2).

\section{Acknowledgements}

We would like to thank the participants and staff of the Ocean Road Cancer Institute (ORCI) located in Dar es Salaam, Kilimanjaro Christian Medical Center (KCMC) located in Kilimanjaro and Bugando Medical Center (BMC) located in Mwanza for their valuable contributions, and J. Coulton for reviewing the manuscript.

\section{Authors' contributions}

LPR and FA were responsible for the conception and design. LPR, ND, GA, ICA, EPM and IJM were responsible for the acquisition of data. LPR, GA, ND, LN, ASN, SLL and FA were responsible for the statistical analyses and interpretation. LPR, GA, ASN and FA wrote the first draft of the manuscript; all authors revised the manuscript for important intellectual content. All authors read and approved the final manuscript.

\section{Funding}

This research received funding from Tanzania Ministry of Education, Science and Technology (MOEST) through 2018 MOEST Sponsorships to Linus Paul Rweyemamu. 


\section{Availability of data and materials}

The datasets generated during and/or analyzed during the current study are available from the corresponding author on reasonable request.

\section{Declarations}

\section{Ethics approval and consent to participate}

This study was approved by the Institutional Review Board of Ocean Road Cancer Institute (reference number 10/Vol/XX/16) and Tanzania National Institute for Medical Research (NIMR) (reference number NIMR/HQ/R.8a/ Vol.IX/3255). All methods were performed in accordance with the relevant guidelines and regulations (Declaration of Helsinki). Participants provided informed consent.

\section{Consent for publication}

Not applicable.

\section{Competing interests}

The authors declare that they have no competing interests.

\section{Author details}

'Department of Molecular Biology and Biotechnology, University of Dar es Salaam, P.O Box 35179, Dar es Salaam, Tanzania. ${ }^{2}$ Mbeya College of Health and Allied Sciences, University of Dar es Salaam, P.O Box 608, Mbeya, Tanzania. ${ }^{3}$ MUHAS Genetic Laboratory, Department of Biochemistry, Muhimbili University of Health and Allied Sciences, P.O Box 65001, Dar es Salaam, Tanzania. ${ }^{4}$ Department of Anatomical Pathology, Muhimbili National Hospital, P.O Box 65000, Dar es Salaam, Tanzania. ${ }^{5}$ Academic, Research and Consultancy Unit, Ocean Road Cancer Institute, P.O Box 3592, Dar es Salaam, Tanzania. ${ }^{6}$ Cancer Genetics and Stem Cell Group, Division of Cancer and Stem Cells, School of Medicine, BioDiscovery Institute, University of Nottingham, Nottingham NG7 2UH, UK. ${ }^{7}$ Department of Rare Diseases, Child Health Institute, Istanbul University, Istanbul 34093, Turkey.

Received: 15 April 2021 Accepted: 8 November 2021

Published online: 20 December 2021

\section{References}

1. Bray F, Ferlay J, Soerjomataram I, Siegel RL, Torre LA, Jemal A. Global cancer statistics 2018: GLOBOCAN estimates of incidence and mortality worldwide for 36 cancers in 185 countries. CA Cancer J Clin. 2018;68(6):394-424.

2. Pace $L E$, Shulman LN. Breast cancer in sub-Saharan Africa: challenges and opportunities to reduce mortality. Oncologist. 2016;21(6):739.

3. Rambau P, Masalu N, Jackson K, Chalya P, Serra P, Bravaccini S. Triple negative breast cancer in a poor resource setting in North-Western Tanzania: a preliminary study of 52 patients. BMC Res Notes. 2014;7(1):1-6.

4. Mansouri H, Mnango LF, Magorosa EP, Sauli E, Mpolya EA. Ki-67, p53 and BCL-2 expressions and their association with clinical histopathology of breast cancer among women in Tanzania. Sci Rep. 2019;9(1):1-11.

5. Komen SG. Tanzania Breast Health Care Assessment: an assessment of breast cancer early detection, diagnosis and treatment in Tanzania. A report carried out on behalf of the Ministry of Health, Community Development, Gender, Elderly and Children of the United Republic of Tanzania.2017.

6. Simpson PT, Reis-Filho JS, Gale T, Lakhani SR. Molecular evolution of breast cancer. J Pathol J Pathol Soc Gr Brit Ire. 2005;205(2):248-54.

7. Algazzar MAA, Elsayed EE-M, Alhanafy AM, Mousa WA. Breast cancer imaging features as a predictor of the hormonal receptor status, HER2neu expression and molecular subtype. Egypt J Radiol Nucl Med. 2020;51(1):1-10.

8. Cho N. Molecular subtypes and imaging phenotypes of breast cancer. Ultrasonog. 2016;35(4):281.

9. Rakha EA, Green AR. Molecular classification of breast cancer: what the pathologist needs to know. Pathology. 2017;49(2):111-9.

10. Hadgu E, Seifu D, Tigneh W, Bokretsion Y, Bekele A, Abebe M, et al. Breast cancer in Ethiopia: evidence for geographic difference in the distribution of molecular subtypes in Africa. BMC Womens Health. 2018;18(1):1-8.
11. Seshie B, Adu-Aryee NA, Dedey F, Calys-Tagoe B, Clegg-Lamptey J-N. A retrospective analysis of breast cancer subtype based on ER/PR and HER2 status in Ghanaian patients at the Korle Bu Teaching Hospital, Ghana. BMC Clin Pathol. 2015;15(1):14.

12. Anothaisintawee T, Wiratkapun C, Lerdsitthichai P, Kasamesup V, Wongwaisayawan S, Srinakarin J, et al. Risk factors of breast cancer: a systematic review and meta-analysis. As Pac J Public Health. 2013;25(5):368-87.

13. Anderson KN, Schwab RB, Martinez ME. Reproductive risk factors and breast cancer subtypes: a review of the literature. Breast Cancer Res Treat. 2014;144(1):1-10

14. Wang JM, Wang J, Zhao HG, Liu TT, Wang FY. Reproductive risk factors associated with breast cancer molecular subtypes among young women in Northern China. BioMed Res Int. 2020;2020:1-9.

15. Britton JA, Gammon MD, Schoenberg JB, Stanford JL, Coates RJ, Swanson CA, et al. Risk of breast cancer classified by joint estrogen receptor and progesterone receptor status among women 20-44 years of age. Am J Epidemiol. 2002;156(6):507-16.

16. Huang W-Y, Newman B, Millikan RC, Schell MJ, Hulka BS, Moorman PG. Hormone-related factors and risk of breast cancer in relation to estrogen receptor and progesterone receptor status. Am J Epidemiol. 2000;151(7):703-14.

17. Williams LA, Casbas-Hernandez P, Nichols HB, Tse CK, Allott EH, Carey LA, et al. Risk factors for luminal a ductal carcinoma in situ (DCIS) and invasive breast cancer in the carolina breast cancer study. PLOS ONE. 2019;14(1):e0211488.

18. Brouckaert O, Rudolph A, Laenen A, Keeman R, Bolla MK, Wang Q, et al. Reproductive profiles and risk of breast cancer subtypes: a multi-center case-only study. Breast Cancer Res. 2017;19(1):1-12.

19. Sisti JS, Collins LC, Beck AH, Tamimi RM, Rosner BA, Eliassen AH. Reproductive risk factors in relation to molecular subtypes of breast cancer: results from the nurses' health studies. Int J cancer. 2016;138(10):2346-56.

20. Lakhani SR, Ellis IO, Schnitt S, Tan PH, van de Vijver M. WHO classification of tumours of the breast. 2012.

21. Elston CW, Ellis IO. Pathological prognostic factors in breast cancer I. The value of histological grade in breast cancer: experience from a large study with long-term follow-up. Histopathology. 1991;19(5):403-10.

22. Hammond MEH, Hayes DF, Dowsett M, Allred DC, Hagerty KL, Badve $\mathrm{S}$, et al. American Society of Clinical Oncology/College of American Pathologists guideline recommendations for immunohistochemical testing of estrogen and progesterone receptors in breast cancer (unabridged version). Arc Pathol Lab Med. 2010;134(7):e48-72.

23. Edge SB, Byrd DR, Carducci MA, Compton CC, Fritz A, Greene F. AJCC cancer staging manual. New York: Springer; 2010.

24. Dey S, Soliman AS, Hablas A, Seifeldein IA, Ismail K, Ramadan M, et al. Urban-rural differences in breast cancer incidence in Egypt (1999-2006). Breast. 2010;19(5):417-23.

25. Errahhali ME, Errahhali ME, Ouarzane M, El Harroudi T, Afqir S, Bellaoui M. First report on molecular breast cancer subtypes and their clinicopathological characteristics in Eastern Morocco: series of 2260 cases. BMC Womens Health. 2017;17(1):3.

26. Alnegheimish NA, Alshatwi RA, Alhefdhi RM, Arafah MM, AlRikabi AC, Husain S. Molecular subtypes of breast carcinoma in Saudi Arabia: a retrospective study. Saudi Med J. 2016;37(5):506.

27. Redondo CM, Gago-Domínguez M, Ponte SM, Castelo ME, Jiang X, García AA, et al. Breast feeding, parity and breast cancer subtypes in a Spanish cohort. PLoS ONE. 2012;7(7):e40543.

28. Mwakigonja AR, Lushina NE, Mwanga A. Characterization of hormonal receptors and human epidermal growth factor receptor-2 in tissues of women with breast cancer at Muhimbili National Hospital, Dar es salaam, Tanzania. Infect Agents Cancer. 2017;12(1):60.

29. Sawe RT, Mining SK, Ofulla AV, Patel K, Guyah B, Chumba D, et al. Tumor infiltrating leukocyte density is independent of tumor grade and molecular subtype in aggressive breast cancer of Western Kenya. Trop Med Health. 2017;45(1):19.

30. Brewster AM, Chavez-MacGregor M, Brown P. Epidemiology, biology, and treatment of triple-negative breast cancer in women of African ancestry. Lanc Oncol. 2014;15(13):e625-34.

31. Effi AB, Koui BS, Koffi KD, Traore ZC, Kouyate M. Breast cancer molecular subtypes defined by ER/PR and HER2 status: association with clinicopathologic parameters in Ivorian patients. As Pac J Cancer Prev. 2016;17(4):1973-8. 
32. Nafissi N, Faraji M, Hosseini M, Shojaee L, Ziaei F, Akbari ME, et al. Relationships between reproductive risk factors for breast cancer and tumor molecular subtypes. As Pac J Cancer Prev. 2018;19(7):1767.

33. Al-Thoubaity FK. Molecular classification of breast cancer: a retrospective cohort study. Ann Med Surg. 2020;49:44-8.

34. Belhadj A, Addou-Klouche L, Benyelles MK, Bendaoud A, Ziane I, Zakmout $B$, et al. Epidemiological study and molecular breast cancer subtypes distribution among West Algerian patients. J Int Res Med Pharm Sci. 2016:6:18-24.

35. Turkoz FP, Solak M, Petekkaya I, Keskin O, Kertmen N, Sarici F, et al. Association between common risk factors and molecular subtypes in breast cancer patients. Breast. 2013;22(3):344-50.

36. Lambertini M, Santoro L, Del Mastro L, Nguyen B, Livraghi L, Ugolini $D$, et al. Reproductive behaviors and risk of developing breast cancer according to tumor subtype: a systematic review and meta-analysis of epidemiological studies. Cancer Treat Rev. 2016;49:65-76.

37. Dall GV, Britt KL. Estrogen effects on the mammary gland in early and late life and breast cancer risk. Front Oncol. 2017;7:110.

38. Lambe M, Hsieh C, Trichopoulos D, Ekbom A, Pavia M, Adami H-O. Transient increase in the risk of breast cancer after giving birth. N Engl J Med. 1994;331(1):5-9.

39. Romieu I, Biessy C, Carayol M, His M, Torres-Mejía G, Ángeles-Llerenas A, et al. Reproductive factors and molecular subtypes of breast cancer among premenopausal women in Latin America: the PRECAMA study. Sci Rep. 2018;8(1):1-10

40. Dianatinasab M, Fararouei M, Daneshi N, Rezaian S, Mohammadianpanah M, Chaman R, et al. Heterogeneity in risk factors for ductal and lobular breast carcinomas: a case-control study. Int J Cancer. 2019;145(11):2917-25

41. Milne RL, Gaudet MM, Spurdle AB, Fasching PA, Couch FJ, Benítez J, et al. Assessing interactions between the associations of common genetic susceptibility variants, reproductive history and body mass index with breast cancer risk in the breast cancer association consortium: a combined case-control study. Breast Cancer Res. 2010;12(6):1-11.

42. Holm J, Eriksson L, Ploner A, Eriksson M, Rantalainen M, Li J, et al. Assessment of breast cancer risk factors reveals subtype heterogeneity. Cancer Res. 2017;77(13):3708-17.

43. Sayed S, Fan S, Moloo Z, Wasike R, Bird P, Saleh M, et al. Breast Cancer risk factors in relation to molecular subtypes in breast cancer patients from Kenya. 2021.

44. Victora CG, Bahl R, Barros AJ, França GV, Horton S, Krasevec J, et al. Breastfeeding in the 21st century: epidemiology, mechanisms, and lifelong effect. Lancet. 2016;387(10017):475-90.

45. Russo J, Hu YF, Yang X, Russo IH. Developmental, cellular, and molecular basis of human breast cancer. JNCI Monogr. 2000;2000(27):17-37.

46. John EM, Hines LM, Phipps Al, Koo J, Longacre TA, Ingles SA, et al. Reproductive history, breast-feeding and risk of triple negative breast cancer: the breast cancer etiology in minorities (BEM) study. Int I Cancer. 2018;142(11):2273-85.

47. Wunderle M, Pretscher J, Brucker SY, Volz B, Hartmann A, Fiessler C, et al. Association between breast cancer risk factors and molecular type in postmenopausal patients with hormone receptor-positive early breast cancer. Breast Cancer Res Treat. 2019:174(2):453-61.

48. Devi CB, Tang TS, Corbex M. Incidence and risk factors for breast cancer subtypes in three distinct South-East Asian ethnic groups: Chinese, Malay and natives of Sarawak. Malaysia Int J cancer. 2012;131(12):2869-77.

49. Fourati A, Boussen H, El May MV, Goucha A, Dabbabi B, Gamoudi A, et al. Descriptive analysis of molecular subtypes in Tunisian breast cancer. Asia Pac J Clin Oncol. 2014;10(2):e69-74.

50. Elgasim MAEA, Abusin HM, Nouri MM. Breast cancer molecular subtypes in relation to age, stage and grade among Sudanese women patients in Khartoum oncology hospital (2013-2017). Int Res J Oncol. 2019;2:1-9.

51. Sengal AT, Haj-Mukhtar NS, Elhaj AM, Bedri S, Kantelhardt EJ, Mohamedani AA. Immunohistochemistry defined subtypes of breast cancer in 678 Sudanese and Eritrean women; hospitals based case series. BMC Cancer. 2017;17(1):804.

52. Chukwuma UJ, Arinze NM, Thaddeus ON, Kenneth EC, Felix EO, Chudi OO, et al. The histological subtypes of breast cancer seen in a tertiary hospital in South-East, Nigeria. Glob J Health Sci. 2020;12(6):93.
53. Iliyasu Y, Atanda AT. Molecular subtyping of carcinoma of the female breast in a tertiary teaching hospital in Northern Nigeria. Ann Trop Pathol. 2019;10(1):20.

54. Omoruyi KA, Nnoli MA, Ebughe GA, Irabor GI, Isiwele EM. Prevalence of molecular subtypes of breast carcinoma in University of Calabar Teaching Hospital using immunohistochemistry as surrogates for intrinsic DNA gene characteristics. 2018.

55. Aman NA, Doukoure B, Koffi KD, Koui BS, Traore ZC, Kouyate M, et al. HER2 overexpression and correlation with other significant clinicopathologic parameters in Ivorian breast cancer women. BMC Clin Pathol. 2019;19(1):1-6.

56. Traoré B, Koulibaly M, Diallo A, Bah M. Molecular profile of breast cancers in Guinean oncological settings. Pan Afr Med J. 2019. https://doi.org/10. 11604/pamj.2019.33.22.18189.

57. Ly M, Antoine M, Dembélé AK, Levy P, Rodenas A, Touré BA, et al. High incidence of triple-negative tumors in sub-saharan Africa: a prospective study of breast cancer characteristics and risk factors in Malian women seen in a Bamako university hospital. Oncology. 2012;83(5):257-63.

58. Mvila GL, Batalansi D, Praet M, Marchal G, Laenen A, Christiaens M-R, et al. Prognostic features of breast cancer differ between women in the Democratic Republic of Congo and Belgium. Breast. 2015;24(5):642-8.

59. Miguel F, Lopes LV, Ferreira E, Ribas E, Pelaez AF, Leal C, et al. Breast cancer in Angola, molecular subtypes: a first glance. Ecancer Med Sci. 2017. https://doi.org/10.3332/ecancer.2017.763.

60. McCormack VA, Joffe M, van den Berg E, Broeze N, dos Santos SI, Romieu I, et al. Breast cancer receptor status and stage at diagnosis in over 1,200 consecutive public hospital patients in Soweto, South Africa: a case series. Breast Cancer Res. 2013;15(5):R84.

61. Bhatia RK, Narasimhamurthy M, Martei YM, Prabhakar P, Hutson J, Chiyapo $\mathrm{S}$, et al. Report of clinico-pathological features of breast cancer in HIVinfected and uninfected women in Botswana. Infect Agents Cancer. 2019;14(1):28.

62. Galukande M, Wabinga H, Mirembe F, Karamagi C, Asea A. Molecular breast cancer subtypes prevalence in an indigenous Sub Saharan African population. Pan Afr Med J. 2014. https://doi.org/10.11604/pamj.2014.17. 249.3305.

\section{Publisher's Note}

Springer Nature remains neutral with regard to jurisdictional claims in published maps and institutional affiliations.

Ready to submit your research? Choose BMC and benefit from:

- fast, convenient online submission

- thorough peer review by experienced researchers in your field

- rapid publication on acceptance

- support for research data, including large and complex data types

- gold Open Access which fosters wider collaboration and increased citations

- maximum visibility for your research: over $100 \mathrm{M}$ website views per year

At BMC, research is always in progress.

Learn more biomedcentral.com/submissions 